\title{
Rickettsiosis Variceliforme o Viruela Rickettsiósica
}

\author{
Alicia Navarro Carrilloa, Pilar Amores Valencianoa, Aranzazu Romero Cebriánª, \\ Mํㅡㄹ Teresa Bartolomé Navarroa ${ }^{a}$ Encarnación Cuesta Vizcaíno ${ }^{a}$
}

\author{
a Especialista en Medicina \\ Familiar y Comunitaria, \\ FEA Urgencias, Hospital \\ General de Villarrobledo, \\ Albacete. \\ Correspondencia: \\ Alicia Navarro Carrillo, C/ \\ Rosario no 98, 6을 \\ 02003 - Albacete, España. \\ Telf.: 627559011, \\ e-mail: lyzzzy@hotmail.com. \\ Recibido el 2 de mayo de 2011. \\ Aceptado para su publicación el \\ 17 de junio de 2011.
}

\section{RESUMEN}

El género de las Rickettsias tiene como característica ser bacterias gramnegativas intracelulares que precisan de un vector para su transmisión. Las fiebres exantemáticas producidas por Rickettsias son endémicas en nuestra región (Albacete), sobre todo en áreas rurales.

Se presenta el caso de un paciente con una variedad inusual de enfermedad producida por Rickettsias, caracterizada por lesiones papulovesiculosas.

Palabras Clave. Rickettsiosis, Rickettsia Akari, Fiebres Exantemáticas.

\section{ABSTRACT}

\section{Varicelliform Rickettsiosis or Rickettsial pox}

Rickettsia is a genus of intracellular, gram-negative bacteria that requires a vector for transmission. Spotted fever caused by Rickettsia is endemic in our region (Albacete), especially in rural areas. We present a patient with an unusual variety of Rickettsial disease, characterised by papulovesicular lesions.

Key Words. Rickettsioses, Rickettsia Akari, Spotted Fever.

\section{INTRODUCCIÓN}

El género Rickettsia está constituido por diferentes especies de bacterias gramnegativas que tienen en común la necesidad de ser parásitos intracelulares. Las rickettsias del grupo de las fiebres exantemáticas son transmitidas por artrópodos que causan una variedad de enfermedades de distribución geográfica limitada, apareciendo fundamentalmente en los meses cálidos del verano ${ }^{1}$.

La lesión característica, la mancha negra, es debida a la reproducción de las bacterias en el interior de las células endoteliales de la zona de la picadura, con necrosis de la dermis y epidermis y edema perivascular.

Una de las presentaciones posibles es la fiebre botonosa mediterránea (FBM), que es endémica en Castilla - La Mancha. Un estudio epidemiológico realizado en Albacete a propósito de la rickettsiosis, demuestra una incidencia de 1,6 casos por 100.000 habitantes/año (9,1 casos por 100.000 habitantes/ año en municipios con menos de 1.000 habitantes). La relación varón/mujer fue 1/4. La incidencia en zonas rurales o personas con animales es mayor ${ }^{2}$. Los estudios de seroprevalencia en otras zonas endémicas demuestran una positividad del 8 al $26 \% 3$.

\section{OBSERVACIONES CLÍNICAS}

Varón de 79 años sin factores de riesgo cardiovascular y como únicos antecedentes quirúrgicos herniorrafia inguinal bilateral y faquectomía bilateral. No recuerda haberse vacunado. Tiene contacto con perros, conejos, hurones y palomas. 
Presenta desde hace 10 días cuadro febril de hasta $39^{\circ} \mathrm{C}$, acompañado de sudoración profusa, episodios de escalofríos y lesión en región glútea izquierda. Se acompaña de dolor osteomuscular generalizado, cefalea, otalgia y tos con expectoración blanquecina. Además, refiere anorexia y astenia secundarias. El paciente había recibido desde hacía 7 días tratamiento con amoxicilina/clavulánico por la lesión glútea, que se había identificado como absceso.

Desde hace 24 horas, además, comienza con lesiones cutáneas generalizadas, junto con la persistencia del cuadro, por lo cual se deriva al servicio de urgencias.

Los datos de exploración física son: eupneico, tensión arterial 129/71 mmHg, frecuencia cardíaca 88 latidos por minuto y temperatura $36^{\prime} 5^{\circ} \mathrm{C}$. Destaca un aceptable estado general, junto con un exantema eritematoso-papular difuso que afecta a zona facial, tronco y extremidades, incluyendo plantas, no descamativo y que desaparece con vitropresión. Se objetivan algunas lesiones microvesiculares. En zona glútea derecha observamos una úlcera necrótica sin exudado purulento, sugestiva de mancha negra (figuras 1 y 2 ). No se destacan otros hallazgos en la exploración cardíaca, pulmonar y abdominal. Los signos meníngeos son negativos.

Tras realizar pruebas complementarias, se observan atelectasias laminares en base izquierda en la radiografía de tórax, siendo los datos más destacados de la analítica: GOT $53 \mathrm{U} / \mathrm{L}, \mathrm{LDH}$ $723 \mathrm{U} / \mathrm{L}$, leucocitos $9.030 / \mathrm{mcl}$ (neutrófilos $78,9 \%$, linfocitos $13,8 \%$, resto de fórmula normal).

El diagnóstico diferencial incluye:

Fiebres exantemáticas: víricas (virus EpsteinBarr, citomegalovirus, hepatitis, varicela, VIH, etc.) y bacterianas (fiebre tifoidea, enfermedad de Lyme, sífilis, rickettsiosis, meningococcemia, etc.).

- Erupción medicamentosa.

- Pitiriasis liquenoide y varioliforme aguda.

Ante la sospecha de infección por Rickettsia, objetivada la lesión típica denominada mancha negra, se pautó tratamiento con doxiciclina 100 $\mathrm{mg} / 12$ horas durante 7 días, desapareciendo los síntomas y las lesiones cutáneas.

En urgencias se solicitó analítica completa con serologías, obteniéndose el resultado días más tarde. En la bioquímica ordinaria destacaba GOT
$75 \mathrm{U} / \mathrm{L}$ y GPT $79 \mathrm{U} / \mathrm{L}$, junto con PCR de $51 \mathrm{mg} /$ dl y VSG de $24 \mathrm{~mm} 1^{\underline{a}} \mathrm{~h}$. Las serologías frente a toxoplasma, citomegalovirus, virus de Epstein-Barr y varicela demostraban infección pasada. Las de Coxiella, lúes, Borrelia burgdorferi, hepatitis y $\mathrm{VIH}$ eran negativas. La serología frente a Rickettsia coronii con IgG positiva a título 1/160, junto con los síntomas, confirmó el diagnóstico.

\section{COMENTARIOS}

La rickettsiosis variceliforme es transmitida por la picadura del ácaro del ratón y no por la de la garrapata como en el caso de la FBM. Es causada por Rickettsia akari y fue descrita inicialmente en Estados Unidos, la ex-Unión Soviética y Corea. Es típica de esta variedad la aparición de vesícula central en las lesiones papulosas. En este caso los síntomas clínicos suelen ser leves y la morbimortalidad infrecuentes. En casos no tratados, los síntomas se resuelven en 2 ó 3 semanas ${ }^{1,3}$. En nuestro caso, las lesiones cutáneas vesículopapulosas plantearon duda diagnóstica con varicela hasta objetivar la mancha negra, dado que el paciente no recordaba haber sufrido infección por este virus con anterioridad.

La edad de presentación más frecuente es en niños y adultos jóvenes, si bien en el estudio epidemiológico realizado en nuestra provincia la edad media fue de 58 años con una desviación estándar de $15^{1,2}$.

En nuestro caso el método diagnóstico serológico fue la inmunofluorescencia indirecta, que no permite diferenciar entre las infecciones producidas por las distintas especies de rickettsias del grupo de las fiebres exantemáticas. Para ello sería necesario aislarlas en cultivo o detectarlas por reacción en cadena de la polimerasa ${ }^{2}$.

\section{BIBLIOGRAFÍA}

1. Fitzpatrick TB, Allen Johnson R, Wolff K, Suurmond D. Atlas en color y synopsis de dermatología clínica. Madrid: McGraw-Hill Interamericana; 2005.

2. Bartolomé J, Lorente S, Hernández-Pérez N, MartínezAlfaro E, Marín-Ors A, Crespo MD. Estudio clínicoepidemiológico de las rickettsiosis del grupo de las fiebres exantemáticas en Albacete. Enferm Infecc Microbiol Clin. 2005; 23(4):194-6.

3. Bernabeu-Wittel, Segura-Porta F. enfermedades producidas por Rickettsia. Enferm Infecc Microbiol Clin. 2005:23(3):163-72. 


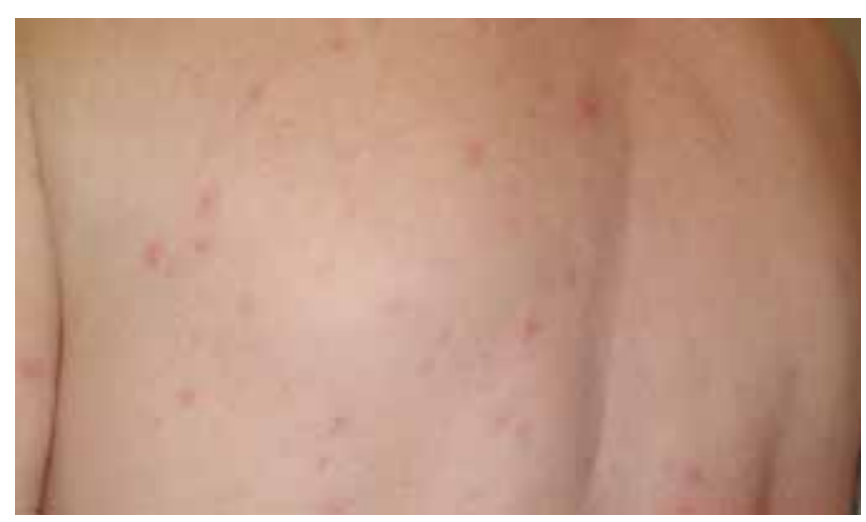

Figura 1. Exantema eritematoso-papular difuso.

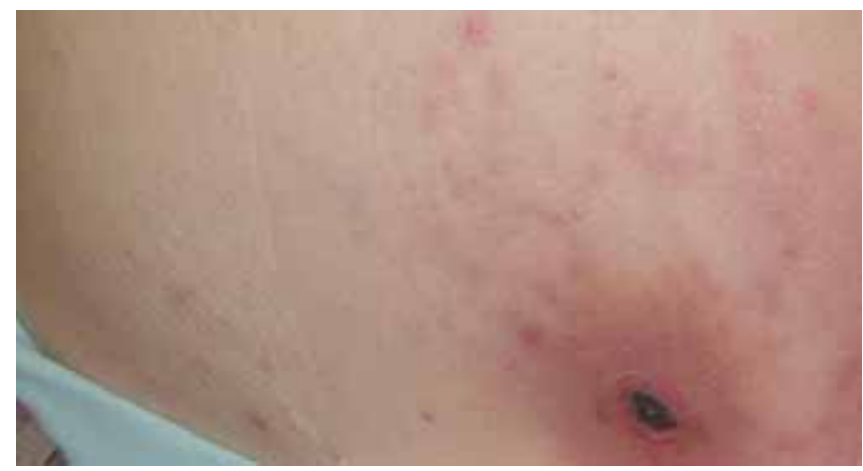

Figura 2. Úlcera necrótica sin exudado purulento, sugestiva de mancha negra. 